\title{
UMA QUESTÃO DE TEMPO: OS USOS DA MEMÓRIA NAS AULAS DE HISTÓRIA
}

\author{
Francisco Régis Lopes Ramos
}

RESUMO: Levando em consideração que, na atualidade, o tema da memória tem ocupado a agenda de movimentos (ou instituiçôes) classificados como "culturais", o texto faz uma reflexão sobre a fundamentação teórica e os procedimentos metodológicos do conhecimento histórico diante do que se convencionou chamar de "direito à memória". Assim, percebe-se que é preciso estabelecer de maneira mais criteriosa as distinções entre os campos rememorativos e a reflexão crítica que a história pode realizar, no sentido de garantir seu papel educativo.

Palavras-chave: Ensino de História. Escrita da história. Memória. Tempo. Literatura.

\section{A MATTER OF TIME: THE USES OF MEMORY IN HISTORY CLASSES}

ABSTRACT: Considering that the theme of memory has now become part of the agenda of movements (or institutions) classified as "cultural", this text reflects on the theoretical base and methodological procedures of the historical knowledge on the so called "right to memory". It thus shows that more careful distinctions should be established between reminding fields and the critical reflection that history can undertake to ensure its educational role.

Key words: History teaching. Writing of history. Memory. Time. Literature.

Doutor em História e professor do Centro de Humanidades da Universidade Federal do Ceará (UFCE). E-mail: regisufc@gmail.com 


\section{O preço do tempo}

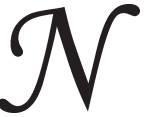

a Semana Santa de 2003, em Fortaleza, a estátua da Praça Capistrano de Abreu sumiu, sem deixar pistas sobre os agentes ou as razões do sumiço. No dia 26 de abril, o jornal $O$ Povo publicou a matéria "Capistrano Mutilado", noticiando que a polícia havia prendido os "ladrōes da estátua". O motivo do roubo era simples: os 150 quilos de bronze. "Sua perna direita foi serrada e já seria vendida a um depósito de sucata”, ressalta o jornalista. Exatamente na data do aniversário, 23 de outubro, o mesmo jornal publicou "A volta de Capistrano":

Enquanto um grupo maior de pessoas prestava atenção à apresentação de um artista popular cantando, outros tentavam vender roupas ou frutas e alguns observavam os retoques no pedestal e preparativos para erguer a estátua de cerca de 150 quilos e 1,90 metros de altura. "Quem é esse aí, hein?". "Ah! O nosso professor voltou". "A perna é de ouro mesmo? Se for, não vai durar essa noite aí no altar", diziam alguns dos populares que se amontoavam na praça da Lagoinha, em busca de um lugar em frente ao pedestal. Tentavam identificar melhor a estátua recuperada.

Seria tarefa dos estudantes e professores de História explicar a biografia de cada estátua ou de cada monumento? Incluir os "lugares de memória” em guias turísticos e livros didáticos? Criar disciplinas de valorização da memória em cursos de graduação ou na educação básica?

Se for levada em consideração a fronteira entre história e memória, essas perguntas, assentadas em preocupaçōes disseminadas nos mais variados territórios institucionais, não teriam somente uma resposta negativa, mas motivariam debates sobre a impropriedade e a legitimidade dos princípios que regeram a formulação do questionamento. As perguntas, portanto, não seriam simplesmente outras, mas estariam sobre outras bases.

Tarefa primeira a ser realizada terá lugar no âmbito do próprio conceito de patrimônio. Não mais defendê-lo como coisa em si, essencialmente pura e boa, mas na qualidade de apropriação do presente envolvido em disputas variadas, que vão da fé de cada um ao bolso de todos. Da religião à economia, dos valores da família aos princípios da coisa pública, em tudo isso se aloja uma tensão nos usos do passado. 
Fazer opções não é fácil e, portanto, exige preparo para quem assume para si alguma responsabilidade administrativa nessa área. Será o primeiro passo de muitos outros reconhecer a complexidade constitutiva do verbo lembrar, afastando a suposta positividade da memória e tornando mais claro o enraizamento temporal do mundo contemporâneo.

Abordar esses lugares de memória no ensino de História não é fácil, exige tato e faro para o palimpsesto e o holograma que há na pele de cada monumento. É imprescindível lidar com deferimentos e desprezos, reverências e irreverências, conforme o rumo das muitas maneiras de imaginar os lugares de uma cidade. Assim, a valorização da memória deixa de ser uma razão a ser defendida para se tornar uma razão a ser debatida.

Ao assumir compromisso com a pluralidade cultural, o ensino de História abre espaço para um tempo instável e apto a perceber a unidade que já não há. Não mais a recordação comum, mas uma tensão sobre o que fazer com o passado; ou, ainda, a angústia em torno do que o passado pode fazer para ausentar o presente. O livro Lavoura arcaica, desse ponto de vista, é um caso dramático. Raduan Nassar expõe, em urdiduras e fímbrias simultâneas, o choque inevitável e incontornável entre o pai e o filho. Cada um emerge no decorrer dos capítulos de modo visceral e envolvente, seduzindo o leitor para os dois lados, ao mesmo tempo. Em contraposição à falta de relógio do filho, o pai faz um longo discurso, que assim se inicia: "O tempo é o maior tesouro de que um homem pode dispor; embora inconsumível, o tempo é o nosso melhor alimento". Sentado à cabeceira da mesa e na frente de um velho relógio de parede, o pai continua sua prédica, esclarecendo que o tempo em tudo está e tudo tem uma ordem. A própria mesa é um exemplo, entre outros: "existiu primeiro uma terra propícia, existiu depois uma árvore secular feita de anos sossegados, e existiu finalmente uma prancha nodosa e dura trabalhada pelas mãos de um artesão dia após dia” (Nassar, 1989, p. 53-54.)

Nessa ânsia paciente de mostrar a eterna ordem do tempo, a pedagogia do pai continua até o fim do capítulo. Em contraposição, o filho confessa: "é enxergando os utensílios, e mais o vestuário da família, que escuto vozes difusas perdidas naquele fosso..." (idem ibid., p. 77-78). Há uma infinidade de conflitos entre duas maneiras de ensinar sobre o passado dos objetos, em sintonia com duas vivências do 
tempo. Para o pai, em sua pregação, trata-se de evitar a desordem que, pouco a pouco, poderia contaminar a vida dos descendentes. Os tempos mergulhados na árvore que virou mesa, ou na mesa que é e não é árvore, tudo isso vem não propriamente de representações desencarnadas, mas sim da própria vida dos personagens. O tempo vivido é exatamente o tempo que ensina a viver: "rico só é o homem que aprendeu, piedoso e humilde, a conviver com o tempo, aproximando-se dele com ternura, não contrariando suas disposições, não se rebelando contra o seu curso, (...) para receber dele os favores e não a sua ira" (idem, ibid., p. 54).

Longe desse tempo exemplar, caminha a vida do filho, em seu trajeto pelos desvãos da recordação. Em contraste com o pai, que sabe da ordem entre passado, presente e futuro, vem o filho do presente múltiplo, que convoca camadas de espaço, aqui e agora:

O tempo, o tempo é versátil, faz diabruras, o tempo brincava comigo, o tempo se espreguiçava provocadoramente, era um tempo só de esperas, me guardando na casa velha por dias inteiros; (...) era um tempo também de sobressaltos, me embaralhando ruídos, confundindo minhas antenas, me levando a ouvir claramente acenos imaginários, me despertando com a gravidade de um julgamento mais áspero, eu estou louco! $\mathrm{E}$ que saliva mais corrosiva a desse verbo, me lambendo as fantasias desesperadas (...). (Nassar, op. cit., p. 95)

É como se o pai tivesse entronizado o bronze em praça pública e o filho, desnorteado e alienado, fosse exatamente aquele que teve a ideia de vendê-lo no quilo, violando a sagrada família da memória.

A lavoura é arcaica, mas perdeu o controle sobre seus frutos. Os usos do tempo vão se revelando no decorrer da narrativa, não somente como expressão das angústias e esperanças diante do passado, mas em uma peleja sem fim entre o dever e a dúvida, entre a dívida e o devir. Penso que é exatamente nesse "quiproquó" que o ensino de História poderá encontrar seu ponto de partida para dialogar com a memória, em uma relação tão indissolúvel e precária como a que se faz entre pais e filhos.

A história diante da memória

Não se deve confundir tema de estudo com defesa de um tema. Pensar que estudar os índios é defender os índios é a mesma coisa que 
imaginar que estudar o nazismo é defender o nazismo. Aliás, nunca é demais repetir que a qualidade da pesquisa (e do ensino) não se mensura pelo tema e sim pela articulação entre problema, teoria, métodos e fontes. Articulação, vale destacar, que se torna densa na medida em que é criadora e criatura da reflexão crítica, feita na liberdade e para a liberdade de se pensar sobre as relaçóes entre passado, presente e futuro. Essas noçôes, tão elementares para quem pesquisa com critérios e compromisso com o saber, precisam ser evidenciadas não somente no ato de pesquisar, mas também quando são observadas as maneiras pelas quais as políticas públicas partem em defesa do dito "patrimônio histórico".

É ingenuidade acreditar que o passado tem como destino dirigir-se ao presente. Pelo contrário, o presente é que insiste em se vincular a um suposto passado passível de ser apreendido, que daria continuidades e diferenças em relação ao que se tem ou ao que se deveria ter, em conexão com o que se quer. A identificação do esquecimento por aqueles que são assediados pelo desejo de lembrar, portanto, é a denúncia da memória que se vê sempre de maneira positiva e bem vinda. O esquecimento esquecido (quer dizer, não percebido) é a transformação, a mudança, a presença do presente que se livra efetivamente do pretérito, não como ruptura radical, mas como movimento que abre espaço para o devir e não dá cabimento aos planos do destino. O esquecimento denunciado, nessa lógica narrativa do cultivo mnemônico, é sempre o vilão, que também tem suas memórias, seus interesses em produzir o passado.

A memória, ao contrário da história, não pensa sobre si mesma de maneira sistemática, não aceita, em princípio, a memória dos outros, porque o direito a ter outras memórias já pressupõe, de alguma maneira, um exercício metódico que caracteriza a história. Mas a história não é simplesmente um saco de gatos. Também está longe de inventários da diversidade, das sínteses conciliatórias ou relativismos da charmosa preguiça que delineia a pós-modernidade.

A memória, sempre pronta para se defender de outras lembranças, faz parte da própria existência de indivíduos e grupos sociais, apresenta soluções de continuidade e rompimento, fundamentais em qualquer configuração cultural. A história não está livre dessas vinculações. Dependendo das filiações, há maior ou menor peso nas alianças com a 
memória, mas sempre emerge uma diferença, através da qual são estabelecidas as fronteiras: a missão da história está em apresentar problemas, não só como fundamento do próprio saber, mas como princípio ético de validação do ato de conhecer.

Em seus apetites pelo passado, história e memória até sofrem a sedução da via conciliatória e não é raro encontrar essa diplomacia, mas, nesses acordos, o que se vê é a diluição das fronteiras e a consequente mistura que passa a justificar sem argumentar, que afirma a diferença sem afirmar o direito à igualdade, criando outras discriminações sociais. Não dá, portanto, para ceder aos apelos impunemente. As cooperações nesse sentido possuem um preço, quase sempre escondido, como se preço não tivessem. Nunca é demais ressaltar que o compromisso do saber histórico tem determinadas exigências, sem as quais o saber deixa de ser historicamente definido.

Enfim, o debate é longo, sobretudo porque é difícil admitir que, apesar de tantas mudanças, continua a valer o etnocentrismo e, portanto, o preconceito discriminador, que procura saldar dívidas do passado com caridades no presente, eliminando noções básicas de análise, como é o caso da luta de classes. Essa penitência mnemônica, com forte apelo sentimental, tem servido muito mais ao mercado da sociedade de consumo do que propriamente para uma transformação realmente efetiva nas relações de dominação cultural.

O mais grave é que a "defesa da memória" acaba caindo em disputas que, ao invés de promoverem o "direito à diferença”, acabam acirrando os ânimos de preconceitos excludentes e o fechamento da percepção diante daquilo que não se adequa a certos padrões. A questão, sempre carente de mais diálogo, torna-se um desafio para a interpretação sobre as lutas sociais e os modos pelos quais a memória assume papel de destaque nas afirmações de grupos em disputa. Cito um caso, descrito e comentado pelo professor Ulpiano Bezerra de Meneses, para mostrar a diferença entre colocar "a identidade como objetivo" ou fazê-la emergir como "objeto do museu":

Há alguns anos, na gestão de Jaime Lerner como prefeito de Curitiba, projetou ele a criação de "portais étnicos" (espaços, nas entradas da cidade, dedicados às diversas colônias de imigrantes que integram a população paranaense). Não conheço detalhes do projeto, pois fui apenas consultado de improviso, numa reunião de museólogos, sobre dificuldades 
que estavam surgindo no entendimento das diversas comunidades entre si. Após reunióes iniciais cheias de cordialidade e expectativas, logo entraram em ação os mecanismos de fronteiras e estabeleceu-se a Torre de Babel pela valorização identitária, às custas da desqualificação uns dos outros. Em resposta à solicitação que me foi feita, respondi que o curso que o projeto havia tomado era previsível e que a única maneira de mudar o rumo era substituir a auto-representação narcisística que de si gerariam os poloneses, os ucranianos, os italianos, os portugueses etc. pela representação que cada comunidade fazia de seu alter ego, ou mesmo de seu "outro situacional": por exemplo, os poloneses dos ucranianos e viceversa, os italianos dos portugueses e vice-versa e entrecruzando os focos. Embora a receita fosse drástica, seria excepcional oportunidade de trazer à luz o que são, para que servem e como funcionam as identidades. (Bezerra de Meneses, 2004, p. 266)

Atualmente, os grupos classificados como "minorias", que buscam delimitar fronteiras a partir dos diferentes pretéritos, estão, certamente, exercitando determinadas maneiras de construir sentido para a vida e para a luta pela vida, mas o próprio conceito de "minoria" pode levar ao jogo perverso da "maioria”. Assim, a memória assume o tom bélico de autoafirmação e, ao mesmo tempo, de negação autoritária de tudo o que compromete aquilo que se afirma. O movimento a favor da diferença descamba para uma cruzada contra a igualdade. Ora, "ser igual" se definiria, em plano ideal, em dar a cada um, de maneira igualitária, o direito de ser diferente, na medida em que a distinção não se transformasse em rebaixamento dos outros.

É por isso que a relação entre "pluralidade cultural" e "ensino de história" vem passando por um momento de debates intensos. Vem se percebendo, por exemplo, que a valorização das chamadas culturas afrobrasileiras ou indígenas pode gerar outros autoritarismos e simplificaçóes, que reproduzem estereótipos e preconceitos que insistem em permanecer. ${ }^{1}$

\section{(Re)sentimento, (re)conhecimento...}

E o ensino da história dos índios e negros no Brasil? Em que sentido deixa de ser história para ser reivindicação mnemônica? Teríamos, então, três histórias (brancos, negros e índios)? A partir de quais fundamentos? Especificamente em relação ao ponto de junção entre identidade e memória, o argumento tem se mostrado frágil e contraditoramente 
preconceituoso. Refiro-me ao argumento que, aqui e acolá, aparece: a "dívida histórica" de um país marcado pelo passado escravocrata e o massacre dos nativos. Ora, falar em dívidas (ou dividendos) é dar trela aos princípios piedosos da história católica ou uma forma de legitimar os postulados do evolucionismo positivista. Não é argumento que ajude a um pensamento antirracista. Além de não contribuir para uma posição crítica sobre as permanências e as transformações que caracterizam as temporalidades que podem ser estudadas no campo da história, há um problema prático a ser respondido. Se a conta existe, quem vai pagar? O pagador seria o próprio presente? E os credores, quem seriam? Escola de negros para negros? De brancos para brancos?

As perguntas valem de modo mais abrangente, ou melhor, para todas as situações nas quais o presente se coloca na categoria de merecedor de reparações ou vítima a espera de restituiçóes. Se fosse descoberta uma fórmula de pagamento, o que, afinal, poderia ser pago? Não seria uma agressão para os que sofreram no passado tratar o sofrimento de um modo tão comercial? Mas, seria justo simplesmente esquecer o que houve? Esquecendo, não estaríamos pecando por omissão? Por outro lado, seria coerente prender-se ao pretérito?

Filhos e netos de torturados são, naturalmente, beneficiários e credores de filhos e netos de torturadores? Se a resposta é positiva, continuamos na lógica da tortura, envolvida em uma rede de culpa e medo que afasta a construção do próprio multiculturalismo. Se a resposta é negativa, o desafio não é pequeno no sentido de construir uma interpretação histórica pronta para aceitar a diferença, mas sem abrir mão da igualdade radical entre todos os seres humanos, sempre com o corpo aberto às potências libertárias, desejosas de futuro, na medida em que a própria memória deixa de ser uma prisão no passado e passa a abrir vias de acesso ao devir.

O tão falado "dever da memória" não pode ficar somente no eterno reclamar de vítimas e na repetição de argumentos judiciários acompanhado por uma querela sem fim entre os descendentes dos descendentes. Não esquecer nunca, isso seria perpetuar ressentimentos e alimentar novos sofrimentos, sobretudo na pele dos que já sofreram. A memória, além de se dirigir ao passado, deveria fazer alianças com um futuro diferente, livre do re-sentimento e, portanto, livre 
para re-pensar. Re-avaliar os critérios que orientaram as denúncias, os julgamentos, as réplicas, as tréplicas, as culpas e as puniçôes. ${ }^{2}$

Comprometer-se com a circulação da crítica da história deveria ser a tarefa dos herdeiros de catástrofes traumáticas, como é o caso da escravidão ou dos regimes autoritários. Estaria no desafio do ensino de História o instável e difícil equilíbrio entre afirmação e negação do passado. O dever da memória seria desvinculado do dever de penitência e o conhecimento sobre o passado passaria a ser responsabilidade (primordial, mas não isolada) do conhecimento histórico, que não se confunde com tribunais, mas não se desvincula de seu fundamento ético de anúncio e denúncia sobre os modos pelos quais os seres humanos se relacionam.

Assim, caberia duvidar não só dos monumentos autoritários, mas da própria ação de dar a algo, a qualquer coisa, o sentido de materialidade memorável. É por isso que Hugo Achugar (2006, p. 169) pergunta: "Democracia é sinônimo de consenso? É desejável o monumento consensual? Talvez, a pergunta-chave seja: as democracias contemporâneas necessitam de monumentos?".

Não é fácil questionar os portadores de memória. Antes de tudo, a lembrança carrega consigo um forte recurso de legitimidade que afasta e nega outras possibilidades de narrar o passado. Exatamente por isso o desafio do saber histórico diante das construções mnemônicas carrega muitas dificuldades, do ponto de vista teórico, no campo dos procedimentos interpretativos e na própria relação dos pesquisadores com o ensino de História, que quer se confundir com "ensino de memória”. Como bem ressalta Durval Muniz, cabe ao historiador a trabalhosa tarefa de violar memórias e gestar a História: "As memórias falam de outros apenas enquanto caminho para falar do próprio indivíduo; a História é trabalho de indivíduos que querem conhecer o outro, interpretá-lo" (Albuquerque Junior, 2007, p. 207).

O direito de "ser outro" aparece na interpretação, quer dizer, emerge no trabalho crítico para se compreender que as lembranças se constituem em tensões sociais, em situações vinculadas aos conflitos de valores e perspectivas. Ao labor historiográfico não caberia, portanto, a aderência a uma causa específica das reivindicações mnemônicas, exatamente porque sua contribuição estaria na capacidade de propor conhecimento sobre a sociedade, explicitando questôes e problemas que 
a sociedade, muitas vezes, não quer mostrar ou simplesmente não deseja saber. Os particularismos das lutas de reivindicação da memória impedem visões comparativas e avaliações mais amplas e profundas no tempo e no espaço (recurso básico em qualquer procedimento investigativo da escrita de história).

A luta pelas "memórias das minorias" seria, então, um nacionalismo em miniatura? Em certos casos, tudo indica que sim. E, em algumas situações, a defesa mnemônica tem se tornado tão autoritária quanto os nacionalismos em tamanho natural.

Nos Parâmetros Curriculares Nacionais (PCN) de História, percebe-se que a memória (ou o patrimônio) tornou-se ponto de pauta, passando a gerar novas práticas de ensino. Mas há um desafio a ser melhor enfrentado. Refiro-me à própria diferença entre história e memória. É nítida a ideia de criticar os monumentos dos "grupos sociais dominantes" e isso se trata, evidentemente, de um procedimento da própria pesquisa histórica. Por outro lado, o verbo criticar parece se reduzir ao verbo ampliar. Assim como ocorre em outros documentos oficiais, sobretudo quando há referências ao "direito à memória", essa linha de raciocínio permite a seguinte conclusão, geralmente abraçada pelas "ONGs": diante do patrimônio da elite excludente, a solução seria resgatar o patrimônio do povo excluído. Há certa insegurança de se colocar a memória como objeto da história:

Um compromisso fundamental da História encontra-se na sua relação com a Memória, livrando as novas gerações da "amnésia social" que compromete a constituição de suas identidades individuais e coletivas.

$\mathrm{O}$ direito à memória faz parte da cidadania cultural e revela a necessidade de debates sobre o conceito de preservação das obras humanas. A constituição do Patrimônio Cultural e sua importância para a formação de uma memória social e nacional sem exclusôes e discriminações é uma abordagem necessária a ser realizada com os educandos, situando-os nos "lugares de memória", construídos pela sociedade e pelos poderes constituídos, que estabelecem o que deve ser preservado e relembrado e o que deve ser silenciado e "esquecido". (Brasil, 1999, p. 54)

O texto não interage de modo mais direto com o conceito de memória, na medida em que não são incorporados alguns debates sobre os modos pelos quais o presente se esforça para lembrar a partir de demandas que identificam séries específicas de esquecimentos. $\mathrm{O}$ 
próprio conceito de "lugares de memória" é tido como algo que pode ser trabalhado no Brasil, como se nossa realidade seguisse o modelo francês.

Um dos "objetivos gerais do ensino fundamental" consiste em "conhecer e valorizar a pluralidade do patrimônio sócio-cultural brasileiro" (idem, ibid., p. 9). Como era de se esperar, o item é reafirmado nos "objetivos gerais de história": "Valorizar o patrimônio sócio-cultural e respeitar a diversidade, reconhecendo-a como um direito dos povos e indivíduos e como um elemento de fortalecimento da democracia” (p. 41). Mais uma vez, a memória aparece nos documentos oficiais como algo a ser valorizado. Os artefatos da lembrança não são vistos na qualidade de documentos históricos. Não se aprofunda a historicidade presente nos usos do passado.

Como bem ressalta François Hartog, as necessidades historicamente constituídas orientaram acepçôes diferenciadas para a chamada "defesa do patrimônio", em direta interação com os modos de contar e nomear períodos, permanências e mudanças (Hartog, 2006, p. 272). Assim sendo, não bastaria somente trocar o verbo valorizar por estudar ou refletir. Seria preciso aprofundar o debate sobre o modo pelo qual se tornaria possível fazer uma história social da memória em atividades compatíveis com os próprios objetivos, no sentido de cultivar a convivência entre culturas diferenciadas. Seria necessário pensar sobre a convivência não como uma consequência simplesmente do "respeito", mas como resultado provisório da reflexão crítica sobre a produção das diferenças, ou melhor, acerca da dinâmica das distinçôes culturais, engendradas em relações da tradição que, além de "respeitadas", devem ser questionadas. Se a memória propicia o reconhecimento, é necessário admitir que a história se faz no conhecimento. Sem as interferências da história, a memória costuma transformar o temporal em eterno, o sentimento em ressentimento.

A produção de memórias e identidades faz parte da defesa da pluralidade cultural. Sobre isso, os PCN trouxeram um avanço significativo, não somente para o ensino de História, mas para a própria prática educativa em sentido mais amplo. Mas, a produção de memórias e identidades múltiplas não é tarefa do ensino de História. O que o saber histórico almeja é perceber a historicidade dessas produçôes, localizando-a em conflitos de experiências e expectativas socialmente constituídas. 
Cito um exemplo: a crítica à participação da igreja católica no processo colonizador não deveria desembocar necessariamente na valorização das religiōes africanas, indígenas ou protestantes. Ao pensamento histórico não caberia valorizações (ou intolerâncias) específicas no campo das crenças. Não estaria em pauta o incentivo à troca de imaginários ou o cultivo de certos simbolismos tradicionais ou reciclados. $\mathrm{O}$ interesse crítico da história seria perceber como as várias religiões são experiências de pessoas que vivem em espaços e tempos específicos, dentro de certas redes de tensões e negociações que envolvem variados interesses. Sobre essa noção de história crítica, os PCN são bem estruturados, mas quando a questão da memória entra em cena, o que se percebe é uma insegurança no sentido de colocar as construções de identidade como objetos da história. A análise, nesse sentido, ganha fôlego somente quando a mira vai para o alvo da "identidade nacional". A reflexão esperada no ensino tende a ser apenas uma espécie de incentivo ao cultivo de outras memórias.

Para se contrapor à história sagrada, histórias profanas. Nada mais consensual. E nada mais polêmico, na medida em que as histórias profanas, pelo fato de não serem religiosas, estão em permanente querela, solicitando sem parar novos desafios. Desse modo, não se pode defender que o combate à história católica vem por uma história protestante, espírita ou afrodescendente, assim como a reflexão sobre as memórias nacionalistas (fabricantes de homogeneidade) não se resolve com o incentivo às memórias das minorias (fabricantes de heterogeneidade). A saída para o ensino de História atento ao respeito pela diversidade cultural não é transformar-se em ensino de memória.

A memória faz parte das lutas políticas. Cabe ao ensino de História fornecer instrumentos para se perceber como isso acontece no tempo e no espaço. Mas a história não é politicamente neutra e sua posição nos PCN aparece claramente, na medida em que se coloca como um saber que se contrapõe a todas as formas de dominação e exploração. A ética, nesse sentido, está no incentivo ao juízo reflexivo que abre espaço para a liberdade, inclusive para questionar a própria historicidade da história, levando-se em consideração que qualquer configuração do presente sobre o passado é parcial. Se fosse possível tudo resumir, poder-se-ia dizer que o objetivo dos estudos históricos é compreender que somos filhos e pais das temporalidades e que nossas opções sempre estão vinculadas ao modo pelo qual lidamos com o tempo. 
Voltemos, então, aos tempos do pai e do filho, tal como se mostram na ficção de Raduan Nassar. O problema é que, no final das contas, as escolhas que se fazem no ensino de História passam necessariamente por concepções de tempo, história e memória. Em nossas aulas, não cabe dar razão ao pai ou ao filho, porque história não é memória.

É preciso entender, portanto, que as reivindicações mnemônicas da atualidade são muito variadas: vão da conservação (ou destruição) de estátuas em praças públicas às lutas de grupos que denunciam as violaçóes dos direitos humanos. Por outro lado, torna-se necessário perceber que a saída para o ensino de História, como tentei mostrar, não estaria somente na valorização dessa diversidade. Não se trata de, simplesmente, fazer um inventário das diferenças. Torna-se tarefa da história interrogar sobre as relações de poder que residem nas produções de sentido para o pretérito, destacando conexões entre casos mais particulares com situaçóes mais gerais.

Ao enfocar as relações de poder residentes na variedade de demandas em torno do pretérito, o professor começa a praticar o debate sobre os modos pelos quais o tempo ganha configuraçóes, por meio de sensibilidades historicamente situadas, que legitimam autoridades e contestações. Autoridades e contestações sobre a maneira de entender o tempo, como pode se perceber na permanente tensão entre pai e filho que Raduan Nassar constrói na sua Lavoura arcaica. Dessa maneira, torna-se mais profunda a reflexão em torno das mudanças e das permanências que se fazem nas relações estabelecidas entre passado, presente e futuro.

Recebido em junho de 2009 e aprovado em novembro de 2009.

\section{Notas}

1. Cito, nesse sentido, as boas análises dos seguintes autores: Siman (2005); Pereira (2008); Flores (2006); Abreu e Mattos (2008).

2. O título do mais recente livro de Marc Ferro é, nesse sentido, bem significativo: $O$ ressentimento na história - compreender o nosso tempo. Indo da Idade Média à explosão das Torres Gêmeas, em 2001, o historiador ressalta que a memória de traumas e promessas descumpridas funciona como elemento decisivo para o entendimento sobre a persistência de estereótipos e a ativação das máquinas de fazer guerra (Ferro, 2009, p. 12). 


\section{Referências}

ABREU, M.; MATTOS, H. Em torno das "Diretrizes curriculares nacionais para a educação das relações étnico-raciais e para o ensino de história e cultura afro-brasileira e africana": uma conversa com historiadores. Estudos Históricos, Rio de Janeiro, n. 41, p. 5-20, 2008.

ACHUGAR, H. Planetas sem boca: escritos efêmeros sobre arte cultura e literatura. Belo Horizonte: Editora da UFMG, 2006.

ALBUQUERQUE JÚNIOR, D.M. História: a arte de inventar o passado. Ensaios de teoria da história. Bauru: EDUSC, 2007.

BEZERRA DE MENESES, U. Memória municipal, história urbana. Revista CEPAM, São Paulo, n. 4, p. 29-33, 1990.

BEZERRA DE MENESES, U. O museu de cidade e a consciência da cidade. In: Museus e cidades - livro do Seminário Internacional. Rio de Janeiro: Museu Histórico Nacional, 2004.

BRASIL. Ministério da Educação. Secretaria de Educação Média e Tecnológica. Parâmetros Curriculares Nacionais: ensino médio: ciências humanas e suas tecnologias. Brasília, DF, 1999.

CATROGA, F. Memória, história e historiografia. Coimbra: Quarteto, 2001.

CHARTIER, R. A história ou a leitura do tempo. Belo Horizonte: Autêntica, 2009.

FERRO, M. O ressentimento na história - compreender o nosso tempo. Lisboa: Editorial Teorema, 2009.

FLORES, E.C. Etnicidade e ensino de História: a matriz cultural africana. Revista Tempo, Rio de Janeiro, n. 21, p. 75-92, 2006.

HARTOG, F. Tempo e patrimônio. Vária História, Belo Horizonte, n. 36, p. 261-274, 2006.

NASSAR, R. Lavoura arcaica. Rio de Janeiro: Record, 1989.

NORA, P. Entre memória e história: a problemática dos lugares. In: Projeto História, n.10. São Paulo: PUC-SP, 1993. 
PEREIRA, J.S. Reconhecendo ou construindo uma polaridade étnico-identitária? Desafios do ensino de história do imediato contexto pós-Lei n. 10.639. Estudos Históricos, Rio de Janeiro, n. 41, p. 2143, 2008.

RAMOS, F.R.L. A danação do objeto: o museu no ensino de história. Chapecó: Argos, 2004.

SIMAN, L.M.C. Representações e memórias sociais compartilhadas: desafios para o processo de ensino e aprendizagem da história. $C a-$ dernos CEDES, Campinas, n. 67, p. 348-364, 2005. 